\title{
Cranial facet joint injuries in percutaneous lumbar pedicle screw placement: a matched-pair analysis comparing intraoperative 3D navigation and conventional fluoroscopy
}

\author{
Marc Hohenhaus $^{1,2}$ (D) Ralf Watzlawick ${ }^{1,2} \cdot$ Waseem Masalha $^{1,2} \cdot$ Florian Volz $^{1,2} \cdot$ Christoph Scholz $^{1,2}$. \\ Ulrich Hubbe $^{1,2} \cdot$ Jan-Helge Klingler ${ }^{1,2}$
}

Received: 31 July 2019 / Revised: 1 April 2020 / Accepted: 12 May 2020 / Published online: 27 May 2020

(C) The Author(s) 2020

\begin{abstract}
Purpose The violation of the cranial adjacent facet is a frequent complication in lumbar instrumentations and can induce local pain and adjacent segment disease. Minimally invasive screw implantation is often stated as risk factor in comparison with open approaches. Percutaneous pedicle screw placement (PPSP) can be performed using single X-ray images (fluoroscopy) or intraoperative 3D navigation. The study compares top-level screws in percutaneous lumbar instrumentations regarding facet violations and screw pedicle position using navigation or fluoroscopy.

Methods Patients after lumbar PPSP were retrospectively separated according to the intraoperative technique: navigation (NAV) or fluoroscopy (FLUORO). Two blinded investigators graded the top-level screws regarding facet violations and pedicle breach in postoperative CT scans. Subsequent matched cohort analysis was performed for comparable groups.

Results Evaluating 768 screws, we assessed 70 (9.1\%) facet violations. Overall, 186 (24.2\%) screws were implanted using navigation. There was no significant difference in the rate of facet violations between both imaging groups (NAV 19/186, $10.2 \%$, FLUORO 51/582, 8.8\%, $p=0.55$ ). Totally, 728 (94.8\%) of all screws showed a correct pedicle position. Most of the 40 unfavorable pedicle positions were placed by fluoroscopy (NAV 4/186, 2.2\%, FLUORO 36/582, 6.6\%, $p=0.03$ ). The matched cohorts verified these results (facet violations: NAV 19/186, 10.2\%, FLUORO 18/186, 9.7\%, $p=0.55$; pedicle penetrations: NAV 4/186, 2.2\%, FLUORO 12/186, 6.9\%, $p=0.04$ ).

Conclusions Both intraoperative imaging techniques allow lumbar PPSP with low rates of cranial facet violations if the surgeon intends to preserve facet integrity. Navigation was superior concerning accurate pedicle screw position, but could not significantly prevent facet violations.
\end{abstract}

Keywords Intraoperative imaging $\cdot$ Fluoroscopy $\cdot$ Navigation $\cdot$ Minimally invasive spine surgery $\cdot$ Facet violation Percutaneous pedicle screw placement

\section{Introduction}

The violation of the cranial adjacent facet joint is a frequent disregarded problem in patients receiving posterior lumbar instrumentations. An injury to the cranial facet caused by the implants can induce local pain and adjacent segment

Marc Hohenhaus

marc.hohenhaus@uniklinik-freiburg.de

1 Department of Neurosurgery, Medical Center, University of Freiburg, Breisacher Strasse 64, 79106 Freiburg, Germany

2 Faculty of Medicine, University of Freiburg, Breisacher Strasse 64, 79106 Freiburg, Germany disease, because it is the first mobile facet adjacent to the performed instrumentation $[1,2]$. The severity of facet violation is variable from compressing the innervated joint capsule to complete penetration of the articulating joint space by the implanted screw thread or head or associated rod. The precise correlation of the extent of violation and clinical affection of the patients has not been well evaluated, but a reduced quality of life as well as a higher reoperation rate has been described [3,4]. Any violation should therefore be avoided.

Overall, the frequency of those injuries is stated with $3.7-30.5 \%$ per screw over all different implantation techniques [5-9]. In open surgical approaches, the rate is reported between $15 \%$ and 20\% [10, 11]. Minimally invasive 
spine surgery is increasingly used due to reduced muscle trauma and local back pain, less intraoperative blood loss, reduced wound healing disorders and a shorter hospital stay with accelerated recovery $[12,13]$. A limitation of minimally invasive approaches is the absence of visual exposure of anatomic landmarks, possibly leading to increased rates of cranial facet violations. Due to oppositional results in several studies, this effect is discussed controversially [1, 6, 8, 14-16].

Percutaneous pedicle screw placement (PPSP) can be performed using single-shot 2D X-ray images (fluoroscopy) or an intraoperative 3D scan and navigation guidance of the instruments. The advantage of intraoperative 3D navigation is a real-time visualization of the local anatomy for an optimal screw implantation trajectory [9]. Concerning the proper screw position within the pedicle, different studies already showed a significant benefit from 3D navigation [17, 18]. Concerning the rate of facet violations, these two methods have scarcely been compared so far [5, 19, 20].

So we wanted to figure out, if the use of intraoperative navigation can reduce the number of cranial facet joint violations in lumbar instrumentations.

\section{Methods}

The aim of the study was to compare the top-level screws in lumbar PPSP regarding facet violations and screw position in the pedicle using intraoperative 3D navigation or conventional fluoroscopy. We assume that navigated screws might show facet joint injuries less frequently.

\section{Study population}

In this retrospective monocentric single-arm cohort study, we included patients who received minimally invasive posterior instrumentation based on lumbar degeneration or infection between January 2006 and May 2015. The trial was approved by the local ethics committee and listed at the national clinical trials register.

Overall, 547 patients undergoing posterior instrumentation involving the lumbar spine within this time period were identified. A total of 163 had to be excluded due to instrumentation up to the thoracic spine or missing followup computed tomography (CT) scans (Fig. 1). In total, 384 patients were eligible for evaluation. Age, weight, size as well as primary indication and applied intraoperative imaging technique were collected from anesthesiological and surgical reports.

\section{Surgical technique}

All operations were done by several surgeons as part of the specialized spinal surgery team of our department with the identical educational background. Surgical procedure of PPSP was performed by tactile exploration of the entry point at the junction of the proximal edge of transverse process and lamina with a Jamshidi needle and therefore absent visibility of anatomic landmarks [21]. In degenerative cases, the implantation of an intervertebral cage was performed (minimally invasive transforaminal lumbar interbody fusion, MIS-TLIF). The groups were separated based on the intraoperative imaging technique: 3D navigation (NAV group) and fluoroscopy (FLUORO group). All operations were performed by surgeons that routinely use both techniques. The use of 3D navigation increased over time, but both techniques were used throughout the inclusion period of the study. The choice of the intraoperative imaging technique was at the surgeon's discretion.

Patients were placed in prone position with standardized pre-surgical preparation. For 3D navigation, lateral and antero-posterior single $\mathrm{X}$-ray images were necessary to place the $\mathrm{C}$-arm in the proper position for the automated 3D scan. First step was a minimal median skin incision for firm fixation of the navigation tracker to the spinous process. Next, intraoperative 3D scan with a dedicated C-arm (e.g., Ziehm Vision FD Vario 3D or Siemens Siremobil Iso-C 3D) was performed. After scanning, computing and transferring the dataset to the navigation system (Stryker), the real-time virtual images guided the referenced Jamshidi needle for identification of the correct entry point and insertion angle for screw implantation. No routine additional intraoperative 3D scan was performed after implantation. Fluoroscopic PPSP was based on conventional lateral and antero-posterior single X-ray images, guiding the Jamshidi needle to the proper implantation position. After bringing the Jamshidi needle through the pedicle into the vertebral body, the position was secured by a Kirschner wire with consecutive implantation of the screw in both techniques. All surgeons intended to preserve the cranial facet integrity.

\section{Outcome measurements}

At our department, all patients receive a CT scan to evaluate bony fusion of the segment one year after surgery. The first eligible CT scan was used for evaluation. Median time between surgery and follow-up CT scan was 347 days [IQR 46-389 days]. Two experienced investigators (MH, JHK), who were blinded for the intraoperative imaging techniques, evaluated the CT scans. Assessment was carried out regarding the position of the top-level screws in relation to the cranial facet joint according to Yson et al. 
Fig. 1 Screened and included numbers of patients as well as categorization of compared groups based on the intraoperative imaging technique in $3 \mathrm{D}$ navigation (NAV) group versus fluoroscopy (FLUORO) group. Furthermore, the subsequent matched cohort analysis is demonstrated based on the matching parameters: age, gender and implantation level

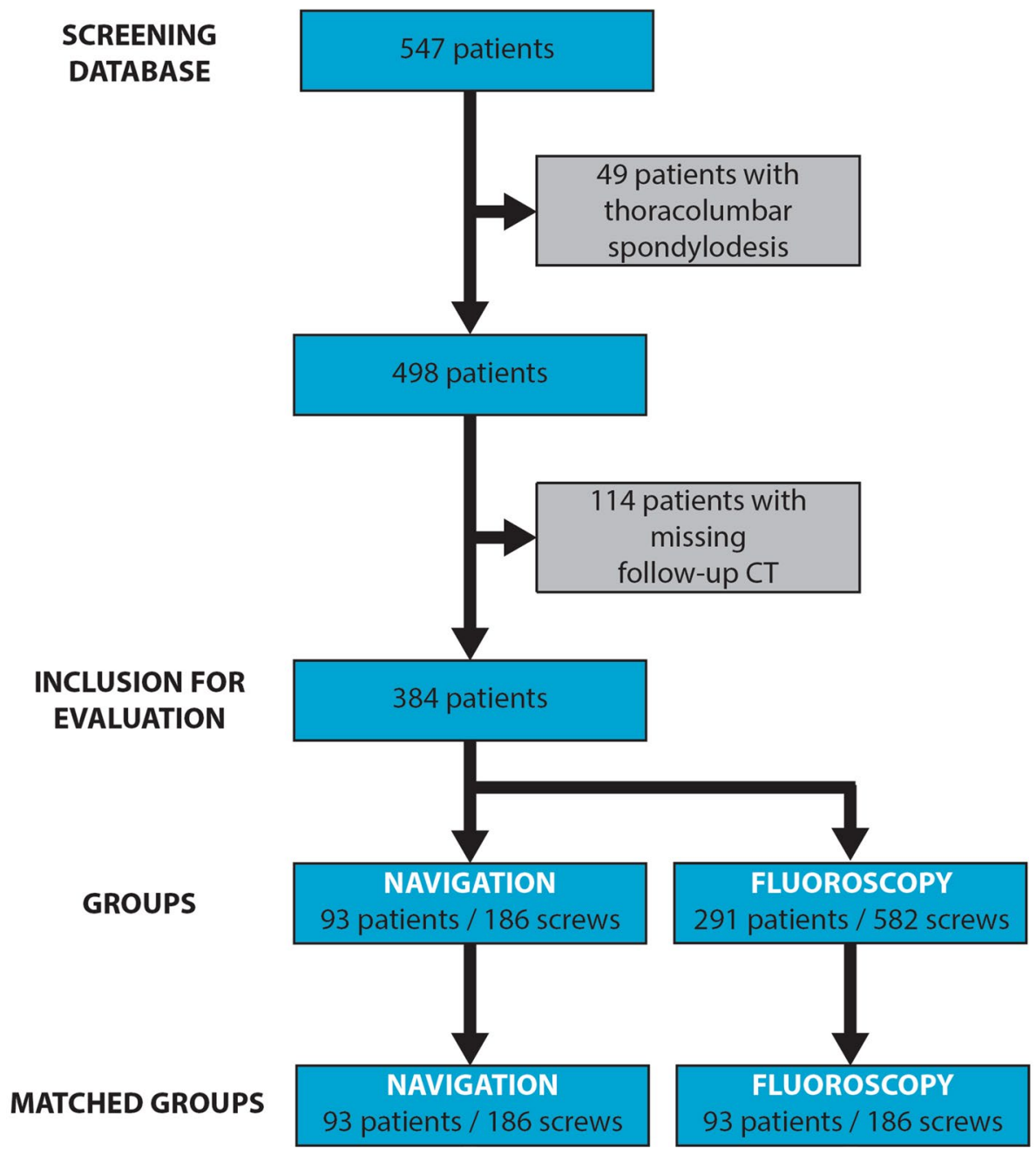

[6]. Furthermore, we evaluated the position of these screws within the pedicle according to Gertzbein et al. [22]. Both scores are illustrated in Fig. 2. The primary endpoint of this study was the incidence of facet violation defined as screw or rod contacting (Yson grade 1) or penetrating (Yson grade 2) the facet joint. As the secondary endpoint, screw penetration of the pedicle wall of more than $2 \mathrm{~mm}$ was defined, corresponding to Gertzbein grade 3-5. These endpoints were assumed as unfavorable.

\section{Interrater reliability}

The interrater reliability for the radiographic outcome parameters was calculated using intra-class correlation (ICC, Cronbach's alpha) for absolute ordinal scales with two raters [23]. The absolute interrater correlation was $97.3 \%$ (737/768 screws) for facet injury grading and $90.8 \%$ (661/768 screws) for pedicle penetration rating. ICC computation showed an excellent correlation for the facet violation ratings with a Cronbach's alpha of 0.910 and an acceptable correlation for the pedicle penetration scores with a Cronbach's alpha of 0.779 . In case of interrater disagreement, the definite score was determined in a consensus evaluation by both raters.

\section{Statistics}

Data processing and statistic analysis were performed with IBM SPSS 25 and the R Project for Statistical Computing. The two groups were compared using chi-square test and Fisher's exact test for metric variables, as well as Mann-Whitney $U$ test for nominal variables of independent samples. $p$ values $<0.05$ were considered to be statistical significant. For evaluation of the several risk factors for facet violation and pedicle penetration, a logistic regression model was applied with multiple testing to receive Bonferroni correction. Significant differences were tested in multiple regression analyses to detect side-influencing factors. 


\section{Grading of facet violations according to Yson et al. [6]}

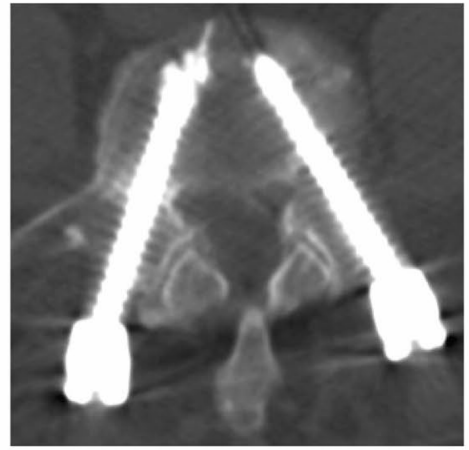

Grade 0

No facet violation

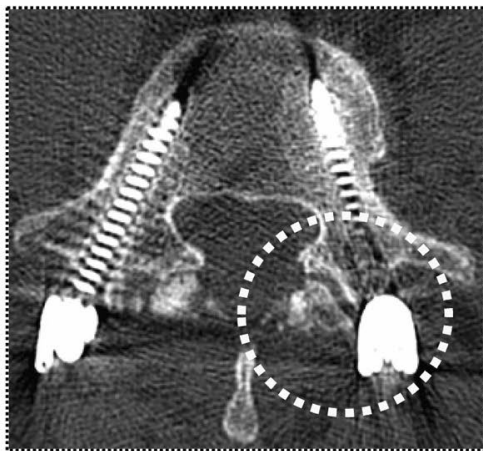

Grade 1

Contact to the facet joint

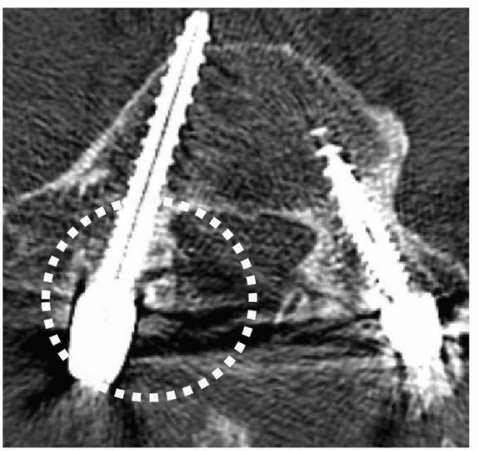

Grade 2

Penetration of the joint space

Grading of screw pedicle perforations according to Gertzbein et al. [22]

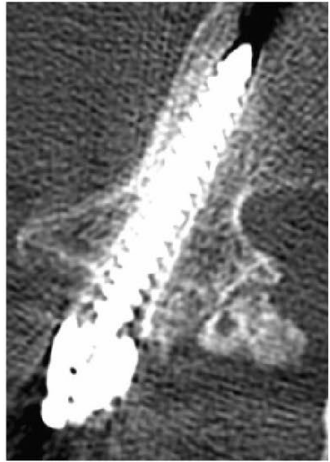

Grade 1

No perforation

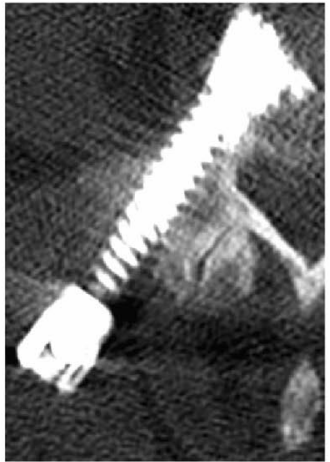

Grade 2

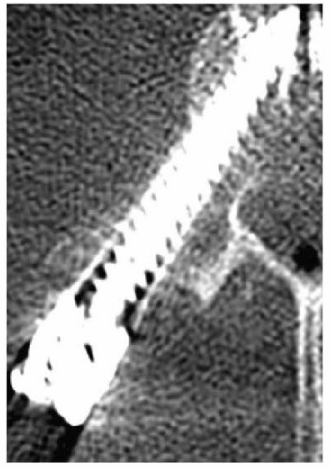

Grade 3

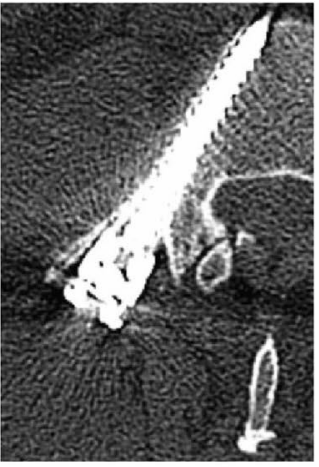

Grade 4

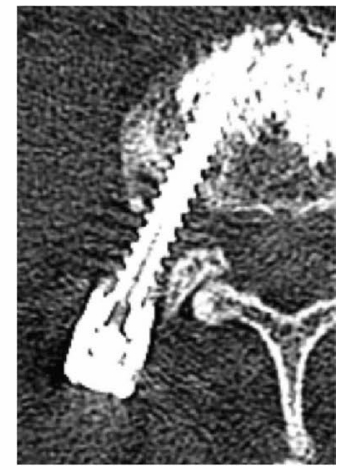

Grade 5

Perforation $<2 \mathrm{~mm}$ Perforation 2 - $4 \mathrm{~mm}$ Perforation $4-6 \mathrm{~mm}$ Perforation $>6 \mathrm{~mm}$

Fig. 2 Depiction of the outcome parameters regarding cranial facet joint violation according to Yson et al. [6] and for screw positioning within the pedicle according to Gertzbein et al. [22]

\section{Matched cohort separation}

For adjustment of the different sample size and heterogeneous lumbar levels in both groups, we performed a matchedpair analysis. Matching parameters were cranial implantation level, age and gender. The applied statistical tests were equal to the evaluation of the whole cohort.

\section{Results}

\section{Baseline characteristics}

A total of 384 implanted cranial vertebral bodies and thus 768 top-level screws because of bilateral instrumentation were analyzed. Median age of all included patients was 66 years [IQR 53-74 years], and 177 (46.1\%) were male (Table 1). The most frequent superior implanted vertebral body was L4 (37.5\%) followed by L5 (25.8\%). The upper lumbar levels were less frequent (L3: $n=70,18.2 \%$; L2: $n=60,15.6 \%$; L1: $n=11,2.9 \%)$. The calculation of the body mass index (BMI) showed a median of $26.8 \mathrm{~kg} / \mathrm{m}^{2}$ [IQR $\left.23.5-30.3 \mathrm{~kg} / \mathrm{m}^{2}\right]$. In $28(7.3 \%)$ patients, the screws were placed because of spondylodiscitis; all other 356 (92.7\%) patients showed a degenerative disease. In 93 (24.2\%) of all patients, an intraoperative 3D scan and navigation was used (NAV group), which corresponds to 186 implanted screws. The other 582 screws were placed using single X-ray images (FLUORO group). These two groups showed no significant differences concerning gender, age, indication, weight, size and BMI (Table 2). The distribution of cranial screw levels was different with a higher proportional amount for navigated instrumentations in the upper lumbar spine (Table 2 and Fig. 3). 
Table 1 Baseline characteristics for all implanted cranial segments

\begin{tabular}{ll}
\hline Number of cranial vertebral bodies & 384 \\
Male & $177(46.1 \%)$ \\
Female & $207(53.9 \%)$ \\
Age, years ${ }^{\#}$ & $66[53-74]$ \\
Size, $\mathrm{m}^{\#}$ & $1.68[1.62-1.76]$ \\
Weight, kg & $77.5[65.3-90.0]$ \\
BMI, kg/m ${ }^{2 \#}$ & $26.8[23.5-30.3]$ \\
Indication & \\
Degeneration & $356(92.7 \%)$ \\
Infection & $28(7.3 \%)$ \\
Cranial vertebral body & \\
L1 & $11(2.9 \%)$ \\
L2 & $60(15.6 \%)$ \\
L3 & $70(18.2 \%)$ \\
L4 & $144(37.5 \%)$ \\
L5 & $99(25.8 \%)$ \\
Implantation technique & \\
Navigation & $93(24.2 \%)$ \\
Fluoroscopy & $291(75.8 \%)$ \\
\hline
\end{tabular}

Four patients $(1.0 \%)$ received screw implantations on two different cranial levels independent from each other

$B M I$ body mass index

${ }^{\#}$ Median [interquartile range]

Table 2 Baseline characteristics in both groups

\begin{tabular}{lllr}
\hline Groups & Navigation & Fluoroscopy & $p$ value \\
\hline Number of screws & 186 & 582 & \\
Male & $84(45.2 \%)$ & $270(46.4 \%)$ & 0.769 \\
Female & $102(54.8 \%)$ & $312(53.6 \%)$ & 0.769 \\
Age, years ${ }^{\#}$ & $68[56-74]$ & $66[53-74]$ & 0.186 \\
Size, $\mathrm{m}^{\#}$ & $1.68[1.62-1.75]$ & $1.68[1.62-1.76]$ & 0.329 \\
Weight, kg & $77.0[67.8-88.5]$ & $78.0[65.0-90.0]$ & 0.723 \\
BMI, kg/m ${ }^{2 \#}$ & $27.7[24.5-31.0]$ & $26.7[23.1-30.0]$ & 0.107 \\
Indication & & & \\
Degeneration & $178(95.7 \%)$ & $534(91.8 \%)$ & 0.072 \\
Infection & $8(4.3 \%)$ & $48(8.2 \%)$ & 0.072 \\
Screw level & & & \\
L1 $(n=22)$ & $12(54.5 \%)$ & $10(45.5 \%)$ & $0.001^{*}$ \\
L2 $(n=120)$ & $56(46.7 \%)$ & $64(53.3 \%)$ & $<0.001^{*}$ \\
L3 $(n=140)$ & $40(28.6 \%)$ & $100(71.4 \%)$ & 0.191 \\
L4 $(n=288)$ & $48(16.7 \%)$ & $240(83.3 \%)$ & $<0.001^{*}$ \\
L5 $(n=198)$ & $30(15.2 \%)$ & $168(84.8 \%)$ & $<0.001^{*}$ \\
\hline
\end{tabular}

There were no significant differences concerning gender, age, size, weight, BMI and indication between the implantation groups. The cranial screw implantation levels were significantly different except for L3. For cranial segments, the navigation was proportionally more frequently used as well as the fluoroscopy for the lower lumbar levels

$B M I$ body mass index

"Median [interquartile range]

*Significant differences with $p<0.05$

\section{Cranial facet violations}

In $70(9.1 \%)$ of all 768 screws, a facet violation was observed, of which 54 presented a contact to the facet joint (Yson grade 1) and $16(2.1 \%)$ penetrated the joint space (Yson grade 2). There was no significant difference concerning the rate of facet violations between the intraoperative imaging techniques (NAV 19/186 screws, $10.2 \%$ vs. FLUORO 51/582 screws, $8.8 \%, p=0.55$, Table 3 ). The logistic regression analysis showed level L2 (OR 2.023, $p=0.016)$ and L5 (OR 2.881, $p<0.001)$ as risk factors for a facet violation (Table 4 ). The respective portion of cranial facet violations for each lumbar vertebral body is shown in Fig. 4. There were no significant associations between other baseline parameters and facet violations.

\section{Pedicle penetrations}

Totally, 728 (94.8\%) implanted screws showed a favorable position within the pedicle (Gertzbein grade 1 and 2), whereas $40(5.2 \%)$ showed a penetration of more than $2 \mathrm{~mm}$. Of these unfavorable screw positions, 21 screws (2.7\%) presented with Gertzbein grade 3, 12 (1.5\%) with grade 4 and $7(0.9 \%)$ with grade 5 . Concerning the distribution between the intraoperative imaging techniques, 36 of all 40 unfavorable screw pedicle positions were in the FLUORO group. The other 4 pedicle penetrations were navigated, resulting in a statistically significant difference between both groups (NAV 4/186 screws, $2.2 \%$ vs. FLUORO 36/582 screws, $6.2 \%$, $p=0.03$, Table 3 ). The logistic regression for pedicle penetration determined L1 (OR 4.383, $p=0.011$ ) as a risk factor (Table 4). The portion of unfavorable pedicle penetrations for each lumbar vertebral body is shown in Fig. 4. The use of intraoperative navigation showed a significant decreased risk for pedicle penetration (OR $0.333, p=0.040$ ). There were no associations between other baseline parameters and pedicle penetration.

\section{Matched cohort analysis}

Because of different distributions of cranial screw levels between both intraoperative imaging groups (Fig. 2), we matched a similar cohort to the navigation group out of all fluoroscopic implanted screws. There were no differences concerning size, weight, BMI or indication between the matched groups. Concerning the radiographic outcome parameters, there was no significant difference for the rate of facet violations between the intraoperative imaging techniques further on (NAV 19/186 screws, $10.2 \%$ vs. FLUORO 18/186 screws, $9.7 \%, p=0.55$ ). For unfavorable pedicle screw positions, the significant advantage of intraoperative 3D navigation guidance was strengthened (NAV 4/186 
Fig. 3 Proportional distribution of the both intraoperative imaging techniques concerning the respective implanted cranial lumbar vertebral bodies

\section{Distribution of the cranial screw levels for both intraoperative imaging groups}

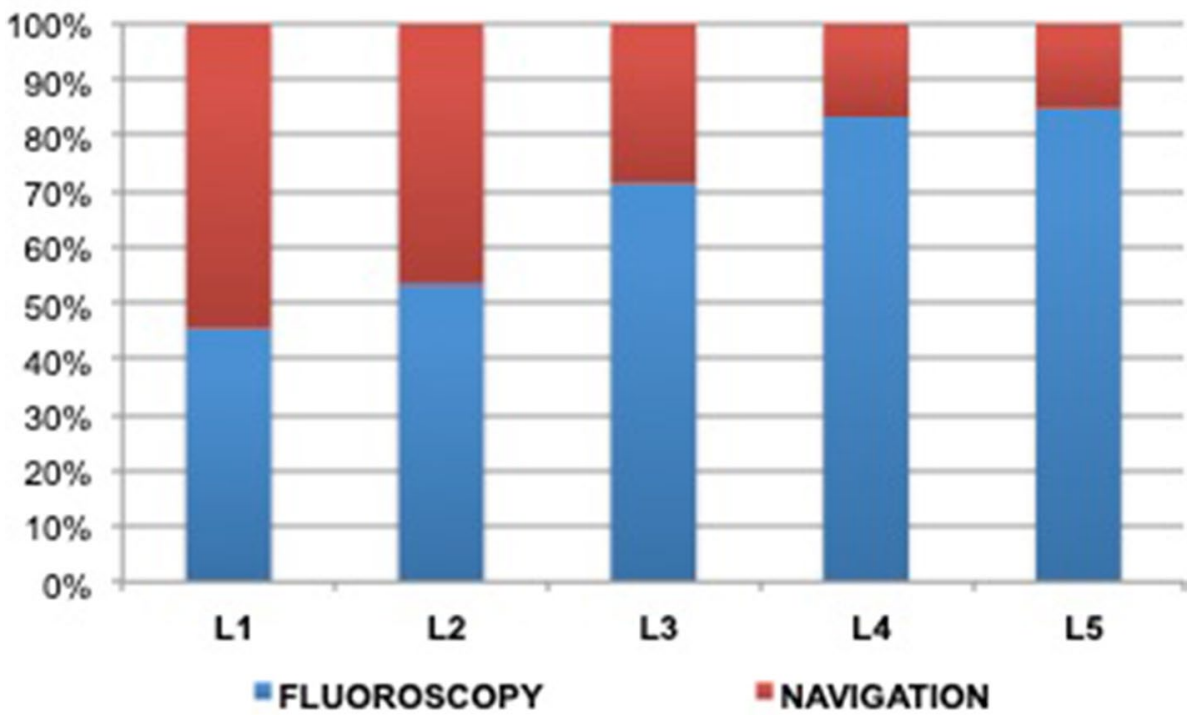

Table 3 Radiographic outcome parameters for all patients

\begin{tabular}{lccc}
\hline All patients & Navigation & Fluoroscopy & $p$ value \\
\hline Number of implanted screws & 186 & 582 & \\
Facet violation & & & \\
Yson 0 & $167(89.8 \%)$ & $531(91.2 \%)$ & 0.549 \\
Yson 1+2 & $19(10.2 \%)$ & $51(8.8 \%)$ & \\
Pedicle penetration & & & \\
Gertzbein 1+2 & $182(97.8 \%)$ & $546(93.8 \%)$ & $0.031 *$ \\
Gertzbein 3-5 & $4(2.2 \%)$ & $36(6.2 \%)$ & \\
\hline
\end{tabular}

A present facet violation was defined as Yson grade 1 or 2 and a pedicle penetration as Gertzbein grade 3, 4 or 5. The NAV group showed a significant reduced rate of pedicle penetrations

*Significant differences with $p<0.05$

screws, $2.2 \%$ vs. FLUORO 12/186 screws, $6.9 \%, p=0.04$, Table 5).

\section{Discussion}

In our cohort, PPSP in dorsal lumbar instrumentations showed comparable low rates of facet violations as reported in open surgical techniques, whereas the intraoperative $3 \mathrm{D}$ navigation could not significantly reduce those facet injuries compared to conventional fluoroscopy.

There are multiple risk factors for the development of postoperative local back pain and adjacent segment disease after posterior lumbar fusions [24-26]. The violation of the cranial facet joint can be one of these components, which, however, can be surgically avoided. In the recent literature, minimally invasive procedures are mostly stated as risk factor, even though there is no solid evidence. In 2011, Park et al. reported a facet violation rate of $31.5 \%$ for percutaneous procedures, which was much higher than the rates in open techniques of about $15 \%[10,16]$. But several former open surgery evaluations reported rates of $20-30 \%$ for all implanted screws [11,27]. Recent studies showed notable reduced rates for facet violations in PPSP of $3.9-12.0 \%[1,6,14,15,19]$. This may be based on an enhanced awareness and training effects for the use of percutaneous techniques.

Direct comparisons of open and percutaneous techniques led to different results. Babu et al. reported a more than four times increased risk for transarticular screw positions in percutaneous $(8.5 \%)$ versus open $(2.0 \%)$ implantations as well as more severe facet injuries [1]. Yson et al., however, reported a decreased rate of facet violations in percutaneous procedures, whereas for all implantations $3 \mathrm{D}$ navigation was used (26.5\% open vs. $4.0 \%$ percutaneous surgery) [6]. These results were bolstered by Obha et al., who reported a decreased rate of facet violations using navigation compared to conventional fluoroscopy in a small cohort of 28 patients receiving PPSP [5].

Lau et al. compared open and percutaneous posterior lumbar fusions and found no significant differences for cranial facet violations. Additionally, an advantage for using intraoperative navigation in percutaneous cases was not found [19]. Current evaluations of percutaneous robotic pedicle screw implantations showed no significant advantages compared to the open technique [20].

Taking all prior studies into account, there is no clear evidence concerning the preferable implantation technique 
Table 4 Risk factor analysis

\begin{tabular}{|c|c|c|c|c|}
\hline & \multicolumn{2}{|c|}{ Risk factors for facet violation } & \multicolumn{2}{|c|}{$\begin{array}{l}\text { Risk factors for pedicle penetra- } \\
\text { tion }\end{array}$} \\
\hline & OR $[95 \% \mathrm{CI}]$ & $p$ value & OR $[95 \% \mathrm{CI}]$ & $p$ value \\
\hline Male & 1.265 [0.774-2.069] & 0.348 & $0.546[0.278-1.076]$ & 0.080 \\
\hline Female & $0.790[0.483-1.292]$ & 0.348 & $1.830[0.929-3.603]$ & 0.080 \\
\hline Age & $0.987[0.962-1.013]$ & 0.314 & $1.013[0.979-1.047]$ & 0.462 \\
\hline BMI & $0.980[0.934-1.029]$ & 0.418 & $0.980[0.921-1.043]$ & 0.533 \\
\hline \multicolumn{5}{|l|}{ Screw level } \\
\hline L1 & $0.467[0.062-3.527]$ & 0.461 & $4.383[1.410-13.621]$ & $0.011 *$ \\
\hline $\mathrm{L} 2$ & $2.023[1,137-3,597]$ & $0.016^{*}$ & $0.761[0.292-1.985]$ & 0.577 \\
\hline L3 & $0.321[0.127-0.812]$ & $0.016^{*}$ & $0.484[0.169-1.382]$ & 0.175 \\
\hline L4 & $0.351[0.188-0.653]$ & $0.001 *$ & $1.246[0.654-2.375]$ & 0.503 \\
\hline L5 & $2.881[1.746-4.754]$ & $<0.001^{*}$ & $0.957[0.459-1.996]$ & 0.908 \\
\hline \multicolumn{5}{|l|}{ Implantation technique } \\
\hline Navigation & $1.185[0.680-2.063]$ & 0.550 & $0.333[0.117-0.949]$ & $0.040^{*}$ \\
\hline Fluoroscopy & $0.844[0.485-1.470]$ & 0.550 & $3.000[1.053-8.543]$ & $0.040^{*}$ \\
\hline Facet violation (Yson 1+2) & - & - & $1.114[0.385-3.228]$ & 0.842 \\
\hline Pedicle penetration (Gertzbein 3-5) & $1.114[0.385-3.228]$ & 0.842 & - & - \\
\hline
\end{tabular}

L2 and L5 are independent risk factors for a facet violation as well as L1 for a pedicle penetration. L3 and L4 showed a decreased risk for a facet violation and the use of intraoperative navigation for a pedicle penetration

$B M I$ body mass index, $O R$ odds ratio, $C I$ confidence interval

*Significant differences with $p<0.05$

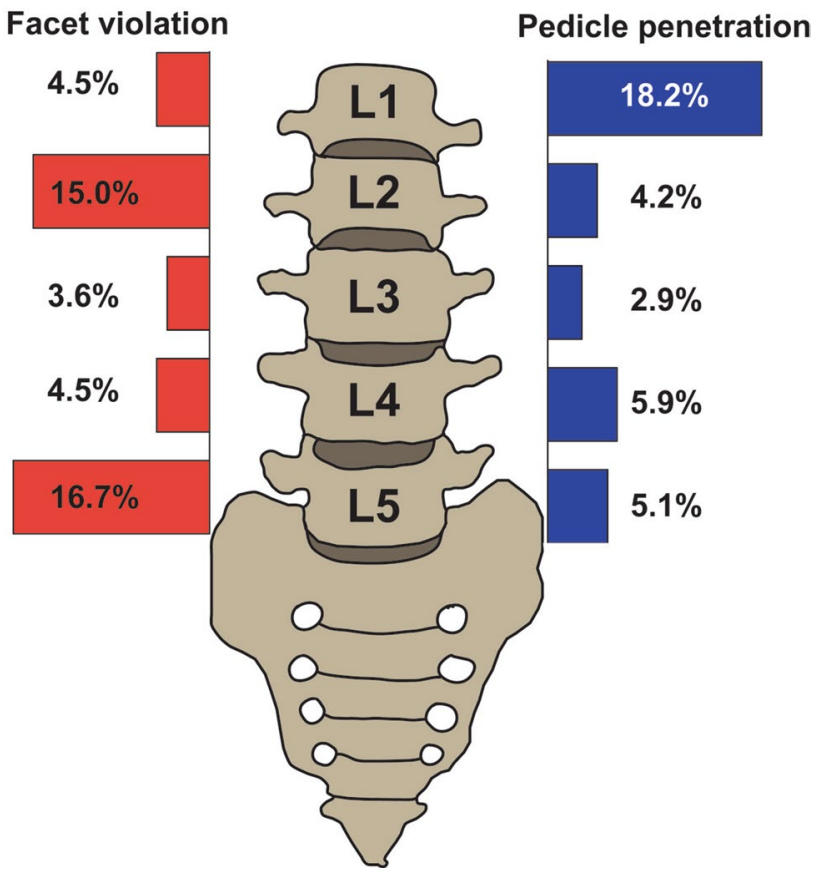

Fig. 4 Rate of implanted screws showing a facet violation (left) or pedicle penetration (right) at the respective implanted cranial lumbar vertebral bodies. L2 and L5 were identified as independent risk factors for a facet violation as well as L1 for a pedicle penetration
Table 5 Radiographic outcome parameters for the matched patient cohorts

\begin{tabular}{llll}
\hline Matched cohort & Navigation & Fluoroscopy & $p$ value \\
\hline $\begin{array}{l}\text { Number of implanted screws } \\
\text { Facet violation }\end{array}$ & 186 & 186 & \\
$\quad$ Yson 0 & $167(89.8 \%)$ & $168(90.3 \%)$ & 0.550 \\
Yson 1+2 & $19(10.2 \%)$ & $18(9.7 \%)$ & \\
Pedicle penetration & & & \\
$\quad$ Gertzbein 1+2 & $182(97.8 \%)$ & $174(93.1 \%)$ & $0.041^{*}$ \\
Gertzbein 3-5 & $4(2.2 \%)$ & $12(6.9 \%)$ & \\
\hline
\end{tabular}

A present facet violation was defined as Yson grade 1 or 2 and a pedicle penetration as Gertzbein grade 3, 4 or 5. The NAV group showed a significant reduced rate of pedicle penetrations

*Significant differences with $p<0.05$

of pedicle screws regarding the rate of facet joint violations. In our patient cohort, the percutaneous technique showed an overall low rate of facet violations with $9.1 \%$ and therefore comparable to the improved quotes found in the recent literature. That seems to be comparable to open procedures too. In case of open surgery, the exposure of anatomic landmarks prevents a major portion of possible facet joint injuries. Our evaluation showed that in spite of the lack of visual anatomic confirmation, PPSP could be done with comparable safety with the use of navigation. The application of navigation is recommended especially 
for a higher accuracy of spinal implantations in minimally invasive surgery [9]. The superior pedicle position of implanted screws has been proven in several studies $[5,17,28-31]$. We assumed that navigation could further reduce the rate of facet injuries too, because of intraoperative $3 \mathrm{D}$ visualization of the bone structures and real-time instrument guidance. But in our patient cohort, there was no significant difference between the NAV and FLUORO group concerning the rate of facet violations.

In our opinion, one of the most important factors to avoid facet violation is to keep in mind that the cranial mobile facet joint is a functional relevant structure that has to be spared. Every spine surgeon should be aware of that. Therefore, the present study aims to strengthen the awareness to preserve the cranial facet joint to further improve the outcome of treated patients, especially in minimally invasive techniques.

Several imaging independent risk factors for the violation of the cranial adjacent facet joint were reported, like alternative entry points for the screw, side-loading systems or implantations in L5 in comparison with the other lumbar bodies $[16,27]$. In our cohort, the highest violation rates were seen in L2 and L5. The L2 is typically characterized with anatomically narrow pedicles and therefore reduced surgical scope for positioning of the screw, resulting in a higher risk for contacting the facet joint. The difficulty for screw insertion in L5 is mostly a far lateral entry point with a flat pedicle angle and limited approach due to the close iliac crest [16]. It is to be assumed that the anatomic configuration has an impact on the correct screw position. A debatable benefit from additional oblique "owl's eye" X-rays in fluoroscopic implantations could not be addressed by our data [32,33].

Additionally, we found that 3D navigation was superior to fluoroscopy in terms of optimal screw pedicle position. This effect was observed in several studies before [5, 17, 29].

A major limitation is the retrospective character of our study, resulting in a heterogeneous distribution of cranial lumbar implantation levels. To address this limitation, we conducted a matched-pair analysis and confirmed our initial findings within the matched cohorts. Furthermore, this work was an exclusively radiographic evaluation. Further studies are needed to analyze clinical consequences in patients with facet violations like increased local pain or adjacent segment disease.

\section{Conclusions}

Percutaneous pedicle screw placement is feasible with comparable rates for facet violations as reported in open surgeries. 3D navigation did not further reduce the rate of facet violations compared to conventional fluoroscopy. The present study confirms 3D navigation to be superior with respect to the optimal placement of the screw within the pedicle.

Acknowledgements Open Access funding provided by Projekt DEAL. Special thanks are due to Dieter Henrik Heiland for the statistical generation of the matched cohort.

\section{Compliance with ethical standards}

Conflict of interest The Department of Neurosurgery has a cooperation agreement with Ziehm Imaging (Nuremberg, Germany) and Stryker Cooperation (Freiburg, Germany). Ulrich Hubbe received financial support for teaching, speaking, consulting, traveling and lodging from Stryker and for speaking, traveling and lodging from Ziehm Imaging. The other authors report no conflict of interest concerning the materials or methods used in this study or the findings specified in this paper.

Ethics statement The trial was approved by the local ethics committee of the University of Freiburg, Germany (Registration Number 445/16), and listed at the German Clinical Trials Register (DRKS00013634).

Open Access This article is licensed under a Creative Commons Attribution 4.0 International License, which permits use, sharing, adaptation, distribution and reproduction in any medium or format, as long as you give appropriate credit to the original author(s) and the source, provide a link to the Creative Commons licence, and indicate if changes were made. The images or other third party material in this article are included in the article's Creative Commons licence, unless indicated otherwise in a credit line to the material. If material is not included in the article's Creative Commons licence and your intended use is not permitted by statutory regulation or exceeds the permitted use, you will need to obtain permission directly from the copyright holder. To view a copy of this licence, visit http://creativecommons.org/licenses/by/4.0/.

\section{References}

1. Babu R, Park JG, Mehta AI, Shan T, Grossi PM, Brown CR et al (2012) Comparison of superior-level facet joint violations during open and percutaneous pedicle screw placement. Neurosurgery 71:962-970

2. Cheh G, Bridwell KH, Lenke LG, Buchowski JM, Daubs MD, Kim Y et al (2007) Adjacent segment disease following lumbar/ thoracolumbar fusion with pedicle screw instrumentation: a minimum 5-year follow-up. Spine 32:2253-2257

3. Park P, Garton HJ, Gala VC et al (2004) Adjacent segment disease after lumbar or lumbosacral fusion: review of the literature. Spine 29:1938-1944

4. Levin JM, Alentado VJ, Healy AT et al (2018) Superior segment facet joint violation during instrumented lumbar fusion is associated with higher reoperation rates and diminished improvement in quality of life. Clin Spine Surg 31:E36-E41

5. Ohba T, Ebata S, Fujita K, Sato H, Haro H (2016) Percutaneous pedicle screw placements: accuracy and rates of cranial facet joint violation using conventional fluoroscopy compared with intraoperative three-dimensional computed tomography computer navigation. Eur Spine J 25:1775-1780

6. Yson SC, Sembrano JN, Sanders PC, Santos ERG, Ledonio CGT, Polly DW (2013) Comparison of cranial facet joint violation rates between open and percutaneous pedicle screw placement 
using intraoperative 3-D CT (O-arm) computer navigation. Spine 38:E251-E258

7. Tian W, Xu Y, Liu B et al (2014) Lumbar spine superior-level facet joint violations: percutaneous versus open pedicle screw insertion using intraoperative 3-dimensional computer-assisted navigation. Chin Med J (Engl) 127:3852-3856

8. Archavlis E, Amr N, Kantelhardt SR, Giese A (2018) Rates of upper facet joint violation in minimally invasive percutaneous and open instrumentation: a comparative cohort study of different insertion techniques. J Neurol Surg A Cent Eur Neurosurg 79:1-8

9. Sembrano JN, Yson SC, Theismann JJ (2019) Computer navigation in minimally invasive spine surgery. Curr Rev Musculoskelet Med 12:415-424

10. Moshirfar A, Jenis LG, Spector LR, Burke PJ, Losina E, Katz JN et al (2006) Computed tomography evaluation of superior-segment facet-joint violation after pedicle instrumentation of the lumbar spine with a midline surgical approach. Spine 31:2624-2629

11. Shah RR, Mohammed S, Saifuddin A, Taylor BA (2003) Radiologic evaluation of adjacent superior segment facet joint violation following transpedicular instrumentation of the lumbar spine. Spine 28:272-275

12. Park Y, Ha JW (2007) Comparison of one-level posterior lumbar interbody fusion performed with a minimally invasive approach or a traditional open approach. Spine 32:537-543

13. Peng CWB, Yue WM, Poh SY, Yeo W, Tan SB (2009) Clini$\mathrm{cal}$ and radiological outcomes of minimally invasive versus open transforaminal lumbar interbody fusion. Spine 34:1385-1389

14. Jones-Quaidoo SM, Djurasovic M, Owens RK, Carreon LY (2013) Superior articulating facet violation: percutaneous versus open techniques. J Neurosurg Spine 18:593-597

15. Knox JB, Dai JM, Orchowski JR (2011) Superior segment facet joint violation and cortical violation after minimally invasive pedicle screw placement. Spine J 11:213-217

16. Park Y, Ha JW, Lee YT, Sung NY (2011) Cranial facet joint violations by percutaneously placed pedicle screws adjacent to a minimally invasive lumbar spinal fusion. Spine J 11:295-302

17. Kosmopoulos V, Schizas C (2007) Pedicle screw placement accuracy: a meta-analysis. Spine 32:E111-E120

18. Nakashima H, Sato K, Ando T, Inoh H, Nakamura H (2009) Comparison of the percutaneous screw placement precision of isocentric C-arm 3-dimensional fluoroscopy-navigated pedicle screw implantation and conventional fluoroscopy method with minimally invasive surgery. J Spinal Disord Tech 22:468-472

19. Lau D, Terman SW, Patel R, La Marca F, Park P (2013) Incidence of and risk factors for superior facet violation in minimally invasive versus open pedicle screw placement during transforaminal lumbar interbody fusion: a comparative analysis. J Neurosurg Spine 18:356-361

20. Park SM, Kim HJ, Lee SY, Chang BS, Lee CK, Yeom JS (2018) Radiographic and clinical outcomes of robot-assisted posterior pedicle screw fixation: two-year results from a randomized controlled trial. Yonsei Med J 59:438-444

21. Klingler J-H, Volz F, Krüger MT, Kogias E, Rölz R, Scholz C et al (2015) Accidental durotomy in minimally invasive transforaminal lumbar interbody fusion: frequency, risk factors, and management. Sci World J 2015:532628

22. Gertzbein SD, Robbins SE (1990) Accuracy of pedicular screw placement in vivo. Spine 15:11-14

23. Hallgren KA (2012) Computing inter-rater reliability for observational data: an overview and tutorial. Tutor Quant Methods Psychol 8:23-34

24. Lee JC, Kim Y, Soh J-W et al (2014) Risk factors of adjacent segment disease requiring surgery after lumbar spinal fusion: comparison of posterior lumbar interbody fusion and posterolateral fusion. Spine 39:E339-E345

25. Kim H-J, Chun H-J, Kang K-T et al (2012) The biomechanical effect of pedicle screws' insertion angle and position on the superior adjacent segment in 1 segment lumbar fusion. Spine 37:1637-1644

26. Atkinson L, Zacest A (2016) Surgical management of low back pain. Med J Aust 204:299-300

27. Chen Z, Zhao J, Xu H, Liu A, Yuan J, Wang C (2008) Technical factors related to the incidence of adjacent superior segment facet joint violation after transpedicular instrumentation in the lumbar spine. Eur Spine J 17:1476-1480

28. Nakashima H, Sato K, Ando T et al (2009) Comparison of the percutaneous screw placement precision of isocentric C-arm 3-dimensional fluoroscopy-navigated pedicle screw implantation and conventional fluoroscopy method with minimally invasive surgery. J Spinal Disord Tech 22:468-472

29. Fraser J, Gebhard H, Irie D, Parikh K, Härtl R (2010) Iso-C/3dimensional neuronavigation versus conventional fluoroscopy for minimally invasive pedicle screw placement in lumbar fusion. Minim Invasive Neurosurg 53:184-190

30. Yang BP, Wahl MM, Idler CS (2012) Percutaneous lumbar pedicle screw placement aided by computer-assisted fluoroscopy-based navigation: perioperative results of a prospective, comparative, multicenter study. Spine 37:2055-2060

31. Bourgeois AC, Faulkner AR, Bradley YC et al (2015) Improved accuracy of minimally invasive transpedicular screw placement in the lumbar spine with 3-dimensional stereotactic image guidance: a comparative meta-analysis. J Spinal Disord Tech 28:324-329

32. Idler C, Rolfe KW, Gorek JE (2010) Accuracy of percutaneous lumbar pedicle screw placement using the oblique or "owl'seye" view and novel guidance technology. J Neurosurg Spine 13:509-515

33. Waschke A, Walter J, Duenisch P et al (2013) CT-navigation versus fluoroscopy-guided placement of pedicle screws at the thoracolumbar spine: single center experience of 4,500 screws. Eur Spine J 22:654-660

Publisher's Note Springer Nature remains neutral with regard to jurisdictional claims in published maps and institutional affiliations. 